\title{
RETURN, RELIABILITY AND RISK AS A PROACTIVE SET OF CONCEPTS IN DEVELOPING AN EFFICIENT INTEGRATION STRATEGY OF COMPANIES
}

\author{
Aleksandras Vytautas RUTKAUSKAS ${ }^{1}$, Aleksandr OSTAPENKO ${ }^{2}$ \\ ${ }^{1}$ Department of Finance Engineering, Faculty of Business Management, Vilnius \\ Gediminas Technical University, Address: Sauletekio al. 11, LT-10223, Vilnius, Lithuania \\ ${ }^{2}$ Department of Economics and Management of Enterprises, Vilnius Gediminas \\ Technical University, Address: Sauletekio al. 11, LT-10223, Vilnius, Lithuania \\ E-mails: ${ }^{1} a l e k s a n d r a s . r u t k a u s k a s @ v g t u . l t ;$ \\ 2 aleksandr.ostapenko@gmx.com (corresponding author)
}

Received 27 November 2015; 02 February 2016

\begin{abstract}
For companies that cannot boast about the abundance of resources available for development, it is particularly important to focus their efforts on the optimum use of such resources and to ensure the reliability of change in the development process to counterbalance the potential losses caused by uncertainty and risk. The article explores the theoretical substantiation for the integral management system of processes covered by the concepts of efficiency, reliability and risk of development. Also, it looks at the practical application of the system through the examination of a specific situation by employing analytical possibilities of a stochastic network. It should also be noted that the concepts of efficiency, reliability and risk are used not only in the assessment of the key development processes of a company but also in the deliberation of the real formation of input as well as its transformation into output results. To formulate and solve the management problems of the complex system, a number of methods were used, namely, the stochastic recording of the aims, the existing restrictions and the stochastic optimisation.
\end{abstract}

Keywords: reliability, risk, stochastic values, processes, fields and networks, stochastic utility function, company development, integration strategy, stochastically informed expertise.

JEL Classification: C00, O10.

\section{Introduction}

In pursuit of the best performance results, a company is faced with various manifestations of uncertainty. The stochastic optimisation logic can be used to find opportunities to create value. A stochastic network is seen as an integral set of stochastic values, stochastic fields and stochastic processes, and the adequate network of utility values. The article aims to suggest an idea for problem formulation concerning the allocation of the development resources of a company among integration strategy attributes, and, using stochastic network models for the adequate description of emerging value possi- 
bilities, to offer specific methods for a solution under uncertainty conditions. The idea is examined by forming a stochastic network of possibilities to create value and providing the network of the usefulness of possibilities for a variety of subjects, so that the most useful variant of change in value creation for a subject could be actually achieved. Together with analytical possibilities, the stochastic network will serve as a visualisation tool for the formation of the problem and a search for solutions. On the other hand, the adequacy of the proposed methodology and algorithms is revealed by their application in optimising the allocation of the company's material investments.

Next, the introduction presents concretisation of the concepts that are used to ensure the adequacy of the problem description and the appropriate selection of quantitative solution methods.

The main concepts used in this chapter - stochastic networks, stochastic processes, stochastic fields - already have their prototypes established in the areas of research, in which these concepts were formed (Hou et al. 2014; Lefebvre 2011; Marin et al. 2012; Wang et al. 2014; Hiraishi 2015). The ideas of value creation have also been formed in research (Schrödl, Turowski 2014; Weaven et al. 2014; Maine et al. 2012; Klibi et al. 2010). When moving away from the areas of research that are structured with respect to these concepts, the ambiguity of these categories and different interpretation of outputs became apparent (Adner, Kapoor 2010; Bechmann, Stine 2013; Bilge et al. 2014). It should be admitted that the perception and use of the categories in the optimum allocation of development resources has not yet matured enough for these concepts to be treated unambiguously. Therefore, the unambiguous assessment of the consequences of solutions is necessary, aiming to discuss the content and substance of the concepts or instruments used in the research to facilitate the adequate understanding of the irreproachability of the obtained solution as well as non-contradictoriness of practical consequences. The concept of a stochastic network has been briefly formulated already and will be examined in greater detail later. To understand the values, processes and the related phenomena of random events, their prototypes from the probability theory were used.

A broader context is required for the explication of the stochastically informed expertise. When creating decision-making schemes and algorithms and using them to assess the decisions related to future possibilities, inadequate measures for the analysis of the perspective are often formed, and misleading solutions are generated. This problem most frequently manifests in works of expertise related to the perspective, i.e. the analysis of future possibilities, etc. The vision generated by experts or estimates provided by expert systems are presented as point or interval estimates, missing out the fact that the efficiency of future possibilities is naturally related to the reliability or disambiguation of possibilities. It can be said that these indicators are accepted as a natural, quantitatively measured feature of future possibilities.

The concept of reliability has deep historical roots for content and quantitative measurement as well as practice. The probability that the quantitatively measured effect of a possibility under analysis $\xi$ will not be smaller than a certain value that we are interested in, $x: P\{\xi \geq x\}=S(x)$, is an established measure of the reliability of possibilities. Where $S(x)$, usually identified as the survival function, is one of the three main functions 
involving the understanding of reliability: density function $P(x)=P\{\xi=x\}$, distribution function $F(x)=P\{\xi<x\}$ and the said survival function $S(x)=1-F(x)$.

Without taking into account the existence objectivity of the reliability concept, the constructiveness of expertise often significantly decreases irrespective of how the estimates are presented, i.e. either in point or interval values. Sometimes, estimates presented in intervals are treated as a full set of the value or process under analysis, i.e. covering all of its possibilities. However, without identifying i.e. disclosing the reliability of each possibility, the interval of possibilities itself would have to be examined as an interval of equally reliable values.

The probability theory, which started the basis of its already axiomatically constructed knowledge almost 400 years ago, used the so-called distribution function logic for the evaluation of the reliability of a possibility, where the possibility of the estimated value is indicated together with the evaluation of the reliability of the possibility.

\section{Stochastic network for investment: a study into the generation of investment technologies and their adequacy}

As provided above, the stochastic network is an integral set of stochastic values, stochastic processes and stochastic fields and an adequate network of utility functions that allows to achieve and compare the usefulness of different random value possibilities (expressed as a possibility effect and its reliability) for a subject. It is usually assumed that each subject has its own utility function. A stochastic network for investment will be understood as the already accepted notion of the stochastic network with its enumerated properties. An exclusive feature of the stochastic network for investment will be the fact that the return on investment will become an analogue to stochastic values, fields and processes (Rutkauskas, Račinskaja 2013; Rutkauskas et al. 2014). Figure 1 shows a geometric image of the stochastic network for investment that consists of two symmetrical components. The case on the left-hand side is where the possibilities of

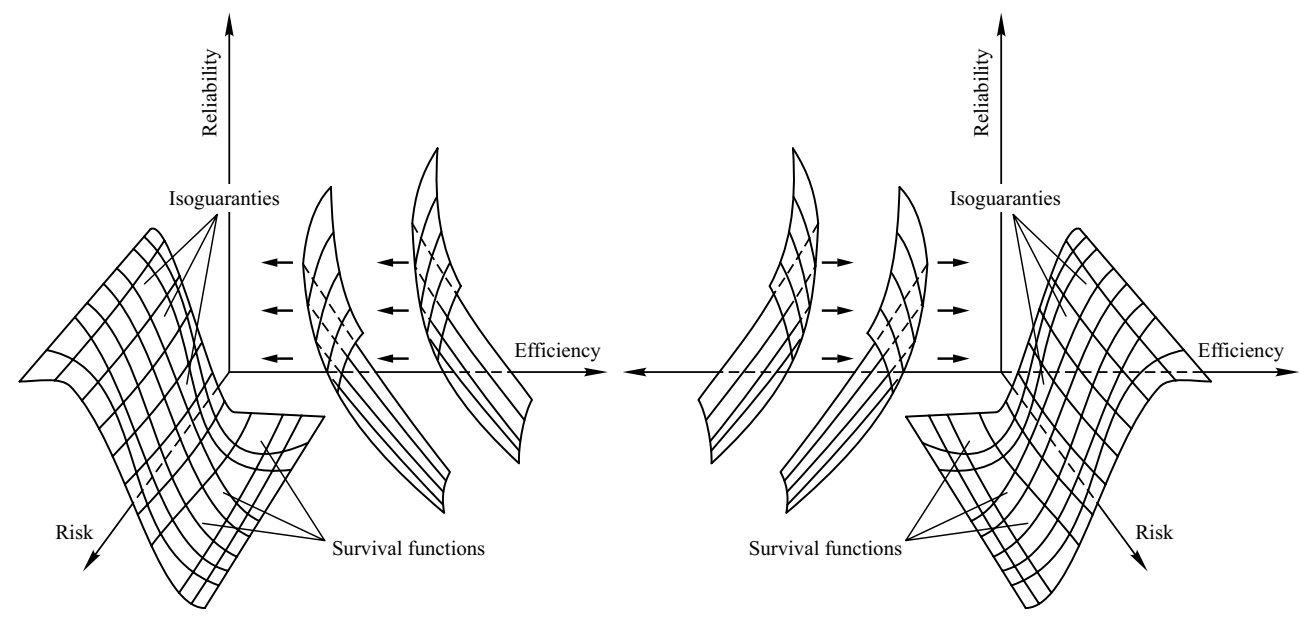

Fig. 1. Stochastic network of investment 
return on investment are evaluated by the possibility effect and the reliability of the effect in any composition. In the case on the right-hand side, the survival function set is replaced with the distribution function set, where these options supplement each other (Rutkauskas, Stasytytė 2011).

It should also be noted that with the help of the stochastic network of investment, adequate investment portfolio functions are performed, i.e. the most suitable possibility is established according to the selected utility function network, which ensures the choice of the most effective possibility. However, it should be pointed out that when selecting certain proportions of an investment portfolio, only a certain random value oriented to the aim is generated, and its real effects depend on the change of market prices.

The following actions are performed in Figure 2, which shows the optimal allocation scheme of the marginal investment unit:

- Figure 2a provides a set of return possibilities of a portfolio formed by the coordinate system content. Here, the possibility risk level is postponed in the abscissa,
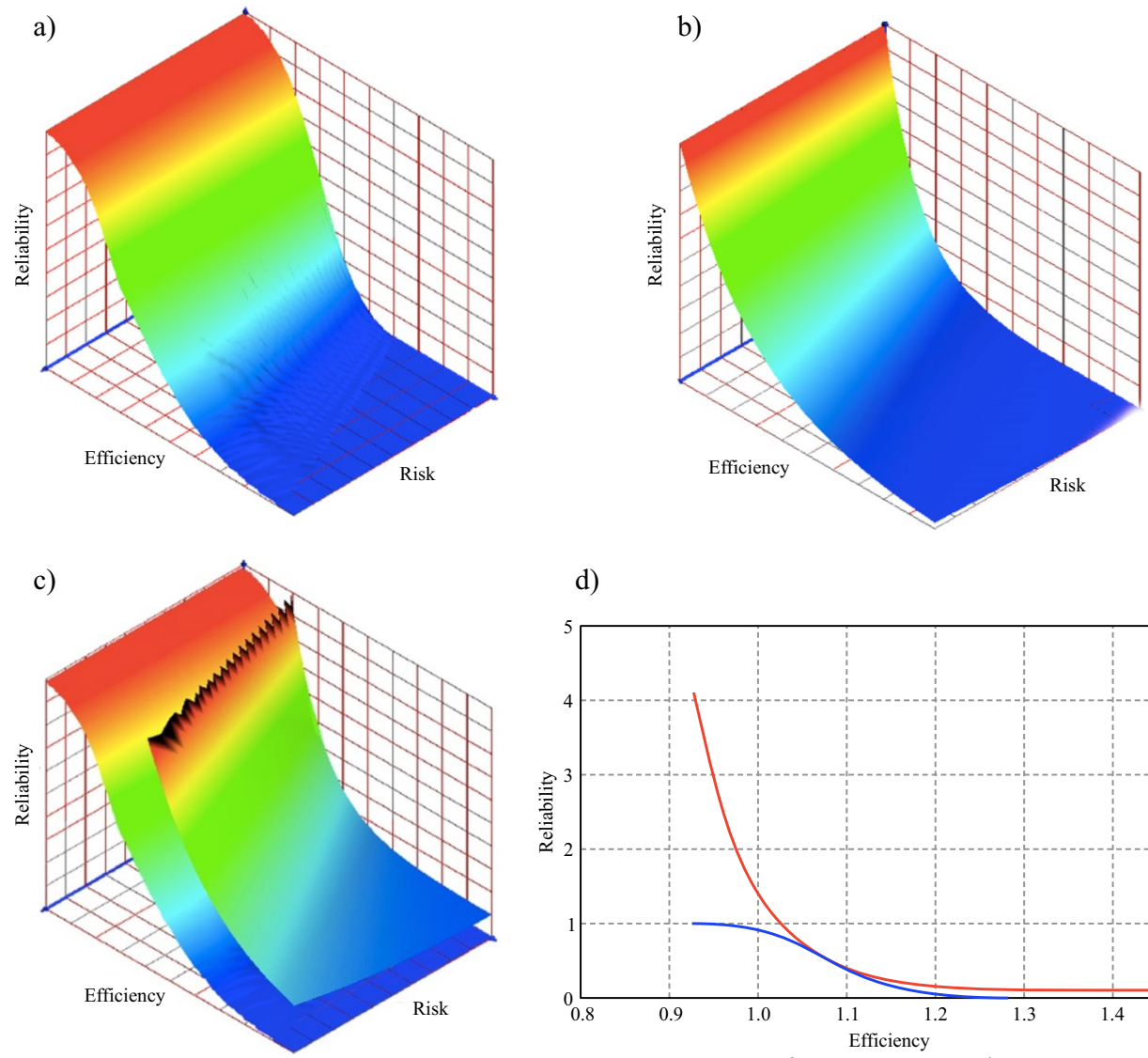

d)

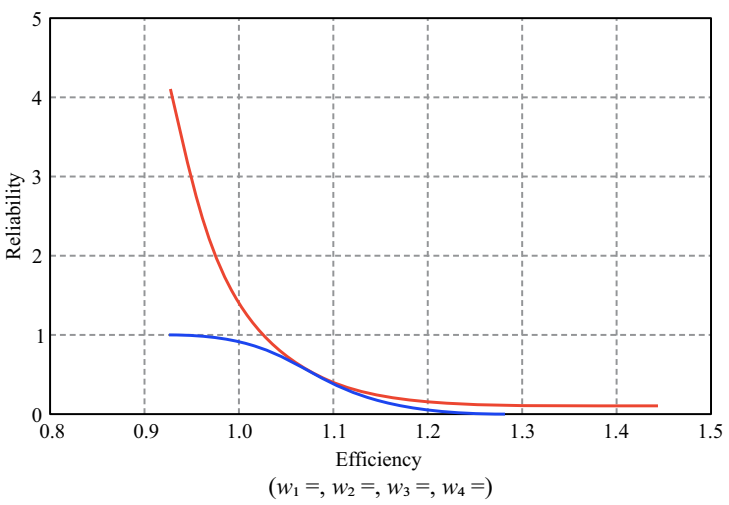

Fig. 2. Allocation scheme of the optimal marginal investment unit: efficiency possibilities (a), utility function (b), surface contact point (c), and optimal solution (d) 
in the ordinate - the efficiency level - in the ordinate, and the reliability level - in the applicate;

- In Figure 2b, a utility function of the subject is formed. Its composition is the same as that of the return possibility surface that has just been discussed;

- In Figure 2c, we have the surface contact point of two possibilities discussed above (Fig. 2a) and the surface of utility possibilities (Fig. 2b), i.e. an optimal solution. It should be noted that the return possibility surface and the surface of utility possibilities are protuberant with respect to each other;

- In Figure 2d, a geometric view of the said optimal point is provided. The survival function is excluded from the set of possibilities and its tangent from the utility set tells at what risk level and, above all, under what allocation structure of an investment unit the optimal solution is obtained, while the effect and reliability values are provided at the intersection point in the abscissa and the ordinate.

So with the structure as to how the marginal investment unit must be allocated among individual assets, we can identify the distribution of the probability of possibilities regarding the integral return on all assets (Fig. 3).

a)

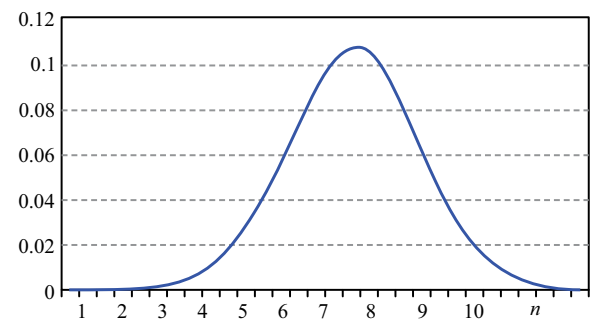

b)

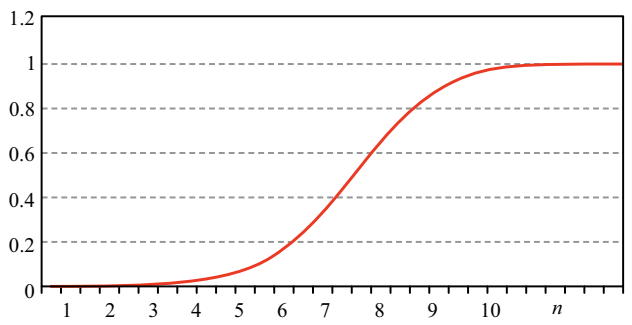

c)

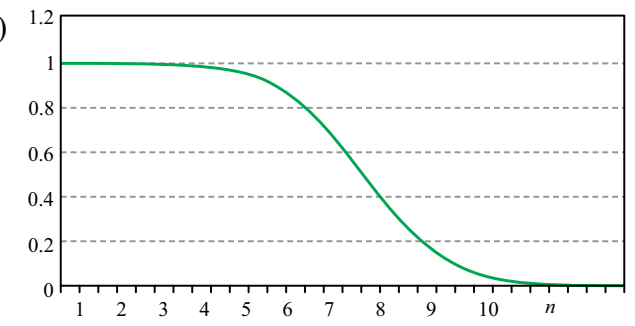

Fig. 3. Distribution of the probability of possibilities regarding the integral multiplier effect: density function (a), distribution function (b), and survival function (c)

Note: In specific cases, specific possibility coordinates are formed in the efficiency and reliability axes.

\section{Adequate investment portfolio as a technical means for identifying an optimal solution}

The concept of a portfolio is used in many areas of research and practical activities. The traditional perception of the investment portfolio as a set of uniform securities owned by a single subject is replaced by a set of various securities owned by a single subject (London et al. 2010). The diversity of relations between changing securities is becom- 
ing very complex. The totality of heterogeneous derivatives in the portfolio alone can create an interaction chain that is hard to unravel. It is not, therefore, surprising that the portfolio management technique is growing more complex regularly and quickly. The portfolio becomes an exceptionally important instrument of systemic analysis, which by its nature is directed to the examination of complex stochastic systems.

In order to disclose the content and possibilities of the adequate portfolio (Rutkauskas 2006), the portfolio should be treated as a natural continuation of the modern or Markowitz portfolio. Markowitz portfolio could be interpreted in a simplified way as follows: let us have $n$ investment assets $A_{1}, A_{2}, \ldots, A_{n}$, which are owned by a subject and generate income expressed in random values $a_{1}\left(\alpha_{1}, \sigma_{1}\right), a_{2}\left(\alpha_{2}, \sigma_{2}\right), \ldots, a_{n}\left(\alpha_{n}, \sigma_{n}\right)$. Here, $\alpha_{i}, \sigma_{i}$ represent: the average $\alpha_{i}$ of the random value $a_{i}$ and the standard deviation $\sigma_{i}$. The subject may assess as to how it should allocate the capital intended for investment between individual assets, i.e. how to select proportions $w_{1}, w_{2}, w_{3}, \ldots, w_{n}\left(\sum_{i=1}^{n} w_{i}=1\right)$, according to which all capital must be allocated between assets. To put in a simplified way, we have a large monetary unit (e.g. one million), and $w_{i}$ indicates parts of the unit. In order to determine the best opportunities for the diversification of the investment capital, it is worthwhile to examine all possibilities that are interesting to us for the allocation of the capital between assets.

In order to find the best option for the diversification of the investment capital, it is simply necessary to review all structural distribution possibilities, i.e. to demand that the structural vectors $\left\{w_{i}^{j}\right\}, i=1,2, \ldots, n ; j=1,2, \ldots, m$ would realistically reflect all capital allocation possibilities between the selected investment assets. In practice, the evaluation of the capital possibilities is performed using the following calculations:

$$
\left\{\begin{array}{c}
w_{1}^{1} a_{1}+w_{2}^{1} a_{2}+\ldots+w_{n}^{1} a_{n}=S^{1} \\
w_{1}^{2} a_{1}+w_{2}^{2} a_{2}+\ldots+w_{n}^{2} a_{n}=S^{2} \\
\ldots \\
w_{1}^{m} a_{1}+w_{2}^{m} a_{2}+\ldots+w_{n}^{m} a_{n}=S^{m}
\end{array}\right.
$$

where $\left(\sum_{i=1}^{n} w_{i}^{j}=1\right)$, for each $j=1,2, \ldots, m$.

$S^{j}, j=1,2, \ldots, m$ are well-diversified portfolio values obtained as asset and allocation coefficient functions. These are random values with their parameters, mean, standard deviation, variation, quartiles, deciles and other quintiles, which directly depend on the distribution of the probability of asset possibilities and their mutual dependence. Where interplay of assets and its result in the portfolio can be accepted as their weighted arithmetic mean, then it is always possible to select such regulation of the transition from vector $\left\{w_{2}^{1}\right\}$ to vector $\left\{w_{2}^{m}\right\}$, so that approaching infinity we could have a consistent chain of random values $S_{1}, S_{2}, \ldots, S_{m}$. As it has already been mentioned, the interplay of assets in the portfolio may not always be adequately described using only a weighted arithmetic mean. The logic of the adequate portfolio also allows us to examine sufficiently complex situations of asset interplay. 


\section{Targeted allocation of development resources to achieve the highest expected efficiency of the integration strategy}

As it was mentioned at the beginning of the article, the focus was on solving the investment problem on how to allocate the marginal investment unit between the assets in the investment portfolio in order for the expected efficiency of the return on the unit would be the highest.

The focus of this section remains similar, except for different formulation of the problem concerned with the allocation of the marginal investment unit between four attributes of the company's integration strategy - product quality, reliability of delivery, process flexibility and cost leadership (Rosenzweig et al. 2003) - to achieve the highest expected performance of the company. Many papers have linked product quality, reliability of delivery, process flexibility and cost leadership to corporate performance (Kim, Arnold 1992; Roth, Miller 1992; Miller, Roth 1994; Vickery et al. 1994; Ward et al. 1995; White 1996; Porter 1996; Hayes, Upton 1998; Flynn et al. 1999). To this end, we will employ the formulation of the created solution as a stochastic optimisation problem and a pragmatic solution using the adequate investment portfolio possibility. It is understood that the vision of the company's performance conveyed by interval estimates given by experts should be transformed into stochastically informed estimates.

Initial intervals are provided by experts and should contain the company's overall performance multipliers nurtured by the strategy. The multipliers should be generated by a conditional marginal investment unit (Table 1).

Table 1. Detailed integration strategy attributes

\begin{tabular}{lccc}
\hline & Min & Average & Max \\
\hline Product quality & 1.075 & 1.0900 & 1.105 \\
\hline Reliability of delivery & 1.050 & 1.0675 & 1.085 \\
\hline Process flexibility & 1.070 & 1.0825 & 1.095 \\
\hline Cost leadership & 1.065 & 1.0775 & 1.090 \\
\hline
\end{tabular}

We had to supplement initial intervals provided by experts with probability distributions describing the reliability of the multiplier values in the intervals. According to the stochastically informed evaluation experience and in coordination with the experts who have determined the intervals, it was agreed that it could or even should be only triangle distributions marked "triangular" (min; max; most likely) in the automated decision packages. Naturally, min and max of the interval serve as distribution values; in the first case, min value of the interval; in the second case, max value of the interval; and in the third case, the most likely value of the middle of the interval. In fact, the triangle distribution can approximate many symmetric distributions and mutual asymmetry cases sufficiently well.

As it has been noted, we may proceed with the following sequence of the situation solution where the most likely distribution values are interval averages (Fig. 4). In Figure 4a, 
by applying the logic of adequate investment portfolio (Rutkauskas 2006), we specify a set of possible solutions in the three-dimensional space; in Figure 4b, we form a utility network for selection of an optimal solution; in Figure 4c, we find the intersection point of two surfaces protuberant with respect to each other, i.e. the highest utility point; in Figure 4d, we identify optimal point coordinates and look for the structure for allocation of investment resources (proportions as to how an investment unit should be divided between integration strategy attributes).

So, with the structure as to how the marginal investment unit is distributed between attributes and the distribution of the possibilities of individual attribute influence multiplier values, we then identify the distribution of the probability of possibilities of the integral multiplier (Fig. 5).

We will then disclose how non-symmetry of the reliability of values derived from the distribution of the probability of possibilities influences the final solution concerning the allocation of development resources between strategy attributes. The situation provided
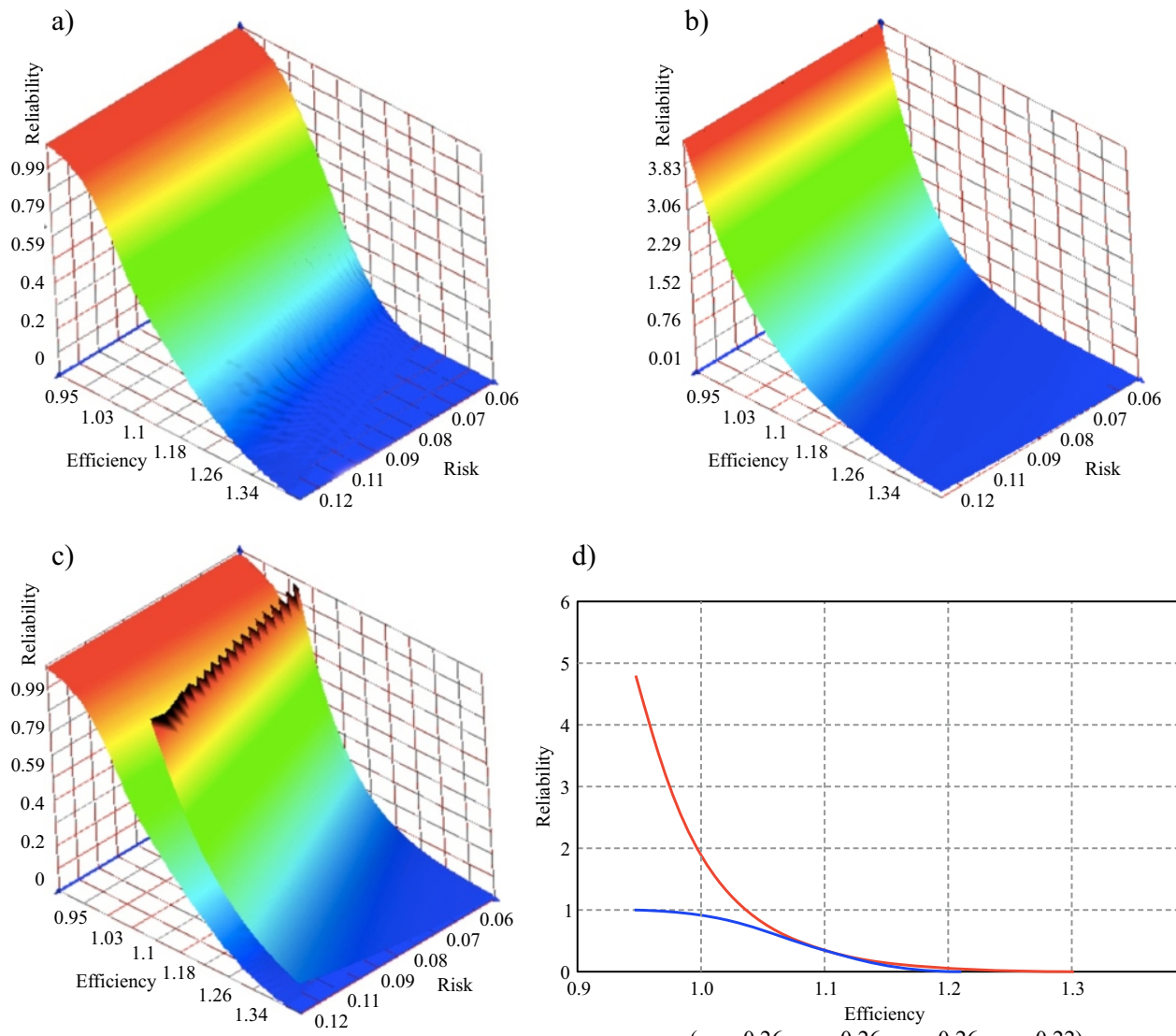

d)

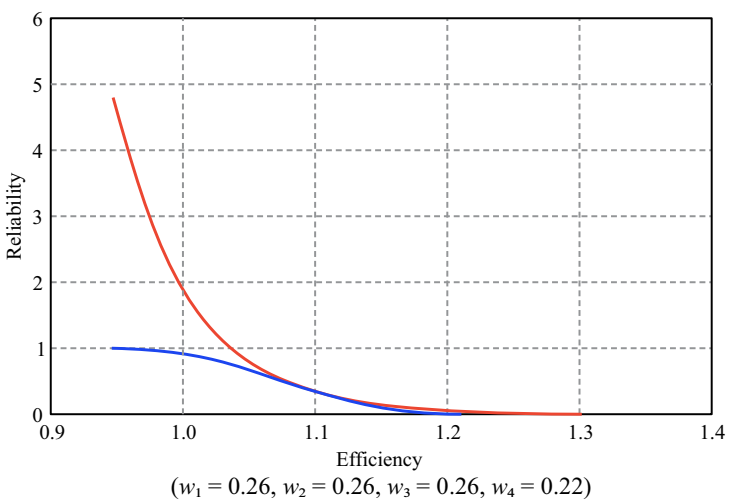

Fig. 4. Scheme of the optimal investment resource allocation, where the highest values of possibilities of probabilities coincide with the interval average: efficiency possibilities (a), utility function (b), surface contact point (c), optimal solution (d) 


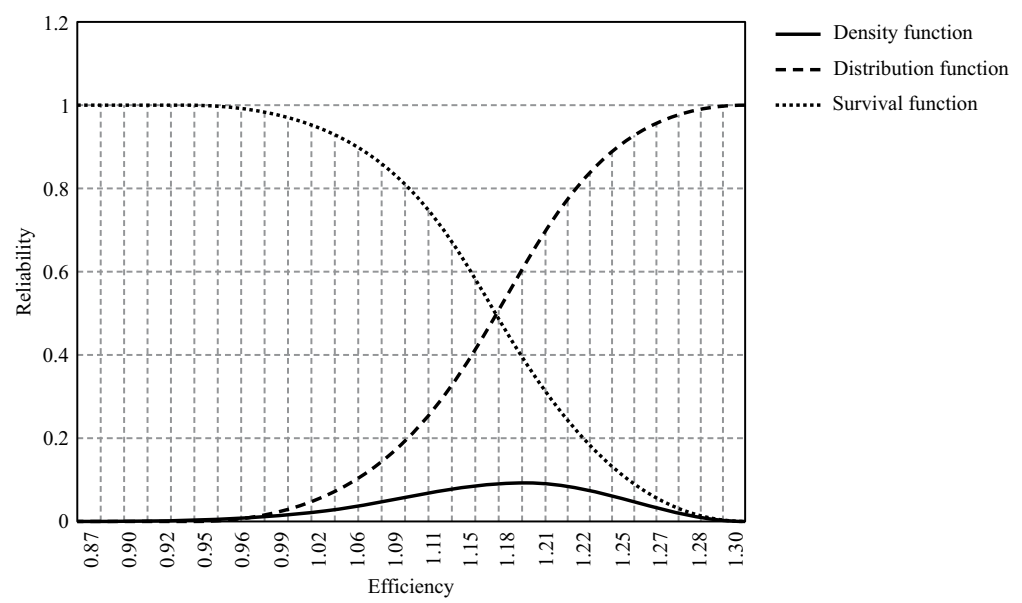

Fig. 5. Distribution of the probability of possibilities of the integral attribute multiplier effect

in Figure 6 was determined by non-symmetry of the distribution of probability of possibilities of triangles i.e. when the most likely value was accepted as not being interval averages. However, in this case, we choose the same utility function:

$$
N=f\left(\frac{e \times P_{e}}{r_{e}}\right),
$$

where $e$ is the possibility of the integral multiplier, $P_{e}-$ the reliability of the possibility, and $r_{e}-$ the risk level of the possibility.

Let us examine the situations where the distribution of the probability of possibilities is not symmetrical. Specifically, let us look at the two cases: 1) where the highest possibility of probability is close to the lower value of the said intervals (min) and 2) where the highest possibility of probability is close to the upper value of the interval (max).

In the first case, the image of the optimal distribution of the marginal development resource unit between integration strategy attributes is provided in Figures $6 \mathrm{a}, 6 \mathrm{~b}, 6 \mathrm{c}$, and $6 \mathrm{~d}$ and fully coincides with Figures $4 \mathrm{a}, 4 \mathrm{~b}, 4 \mathrm{c}$, and $4 \mathrm{~d}$, while the content of Figure 6e coincides with Figure 5.

In the second case, the image of the optimal distribution of the marginal development resource unit between integration strategy attributes is provided in Figure 7.

We can quantitatively compare Figures 6 and 7 and see how the non-symmetry of the distribution of the probability of possibilities influences the final result, i.e. how the set of integral multiplier possibilities changes as well as the form of the distribution of the probability of possibilities.

So, having ensured the reliability of expert evaluations and the adequacy of the stochastic utility function, we can generate significant information about the distribution of strategic development resources between the attributes that determine the final integration strategy effect. 
A. V. Rutkauskas, A. Ostapenko. Return, reliability and risk as a proactive set of concepts in developing ...
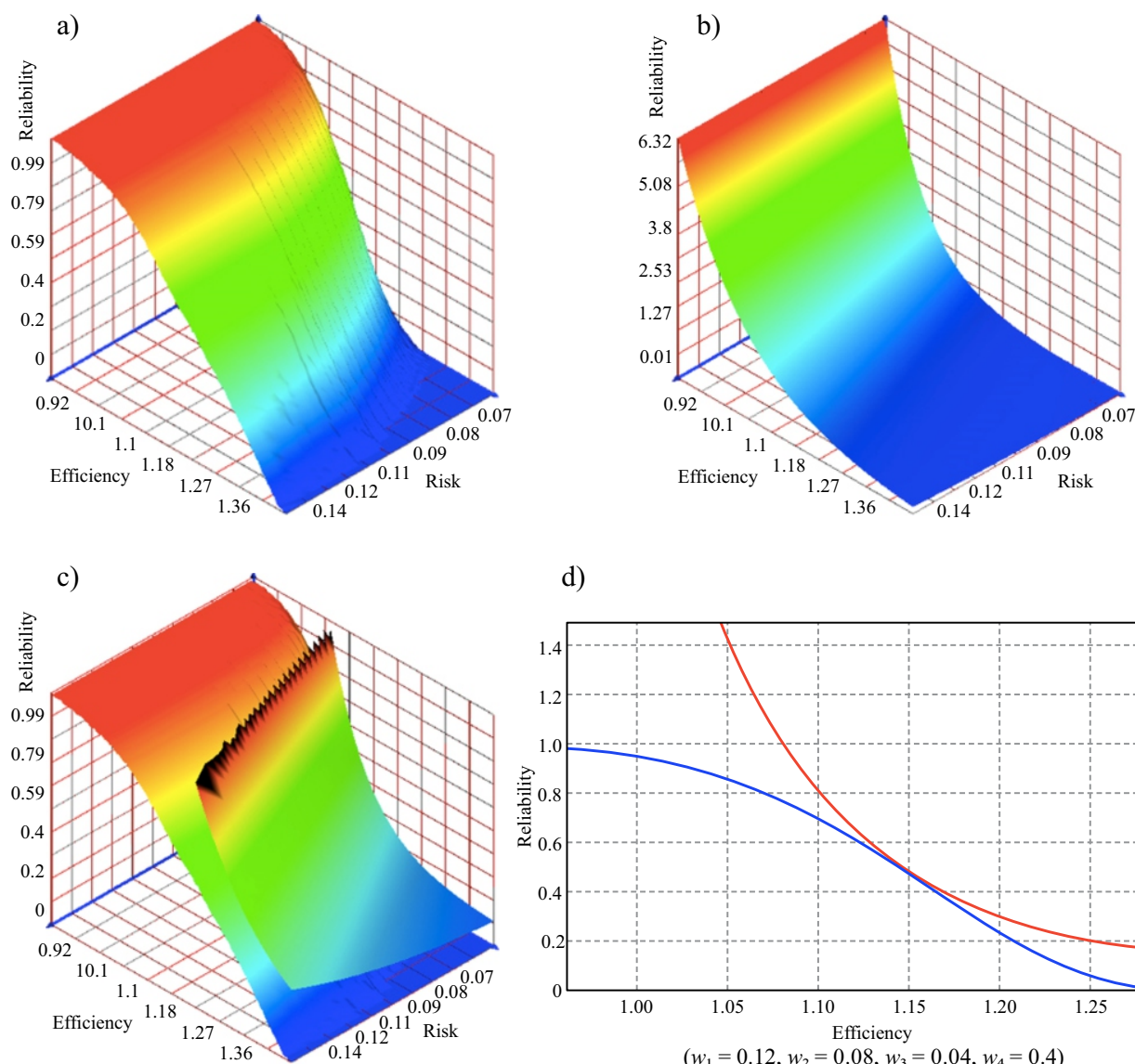

d)

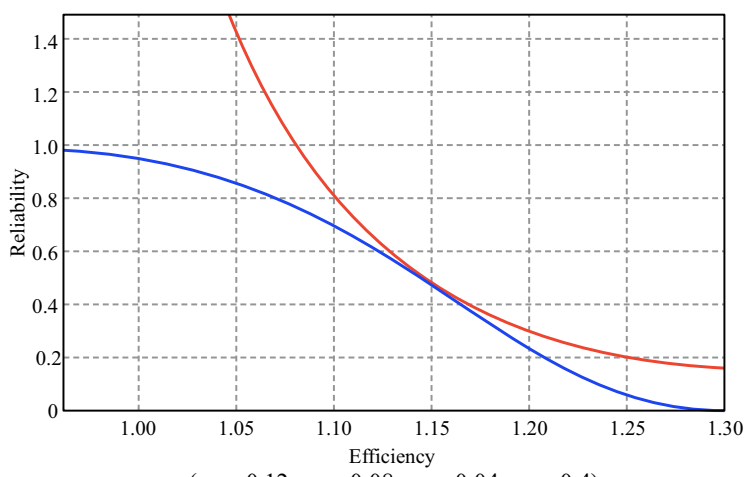

$\left(w_{1}=0.12, w_{2}=0.08, w_{3}=0.04, w_{4}=0.4\right)$

e)

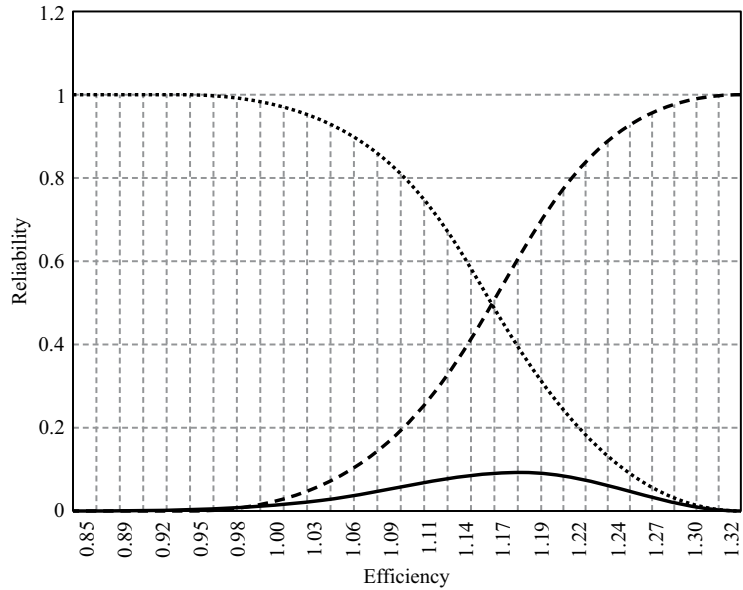

Density function

- - Distribution function

....... Survival function

Fig. 6. Scheme of the optimal investment resource allocation between strategy attributes where the highest possibilities of probabilities coincide with the lowest values of intervals: efficiency possibilities (a), utility function (b), surface contact point (c), optimal solution (d), and the distribution of the probability of possibilities (e) 

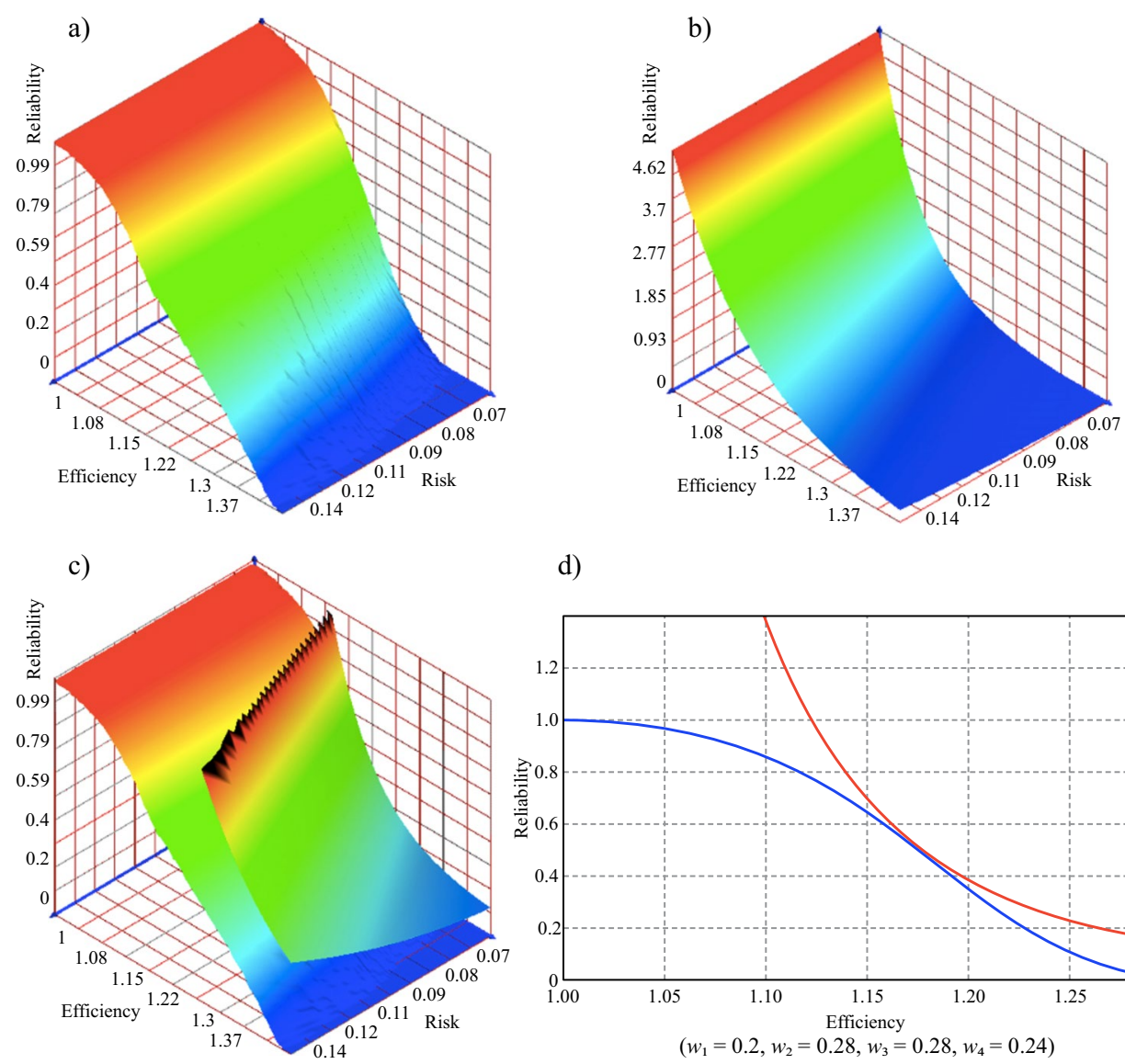

d)

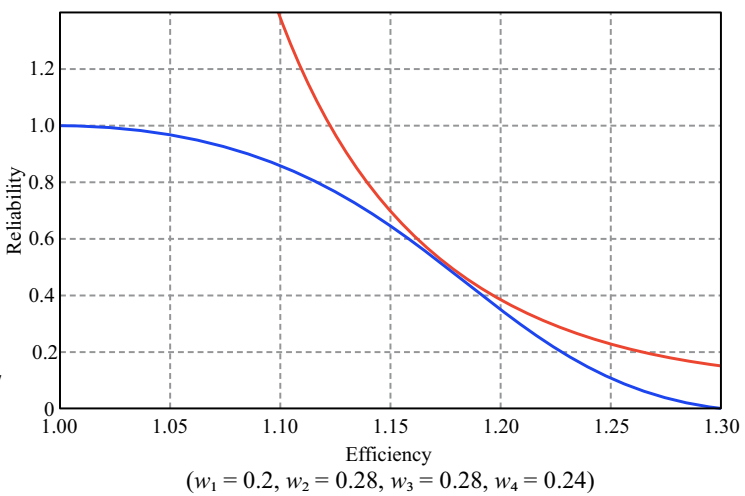

e)

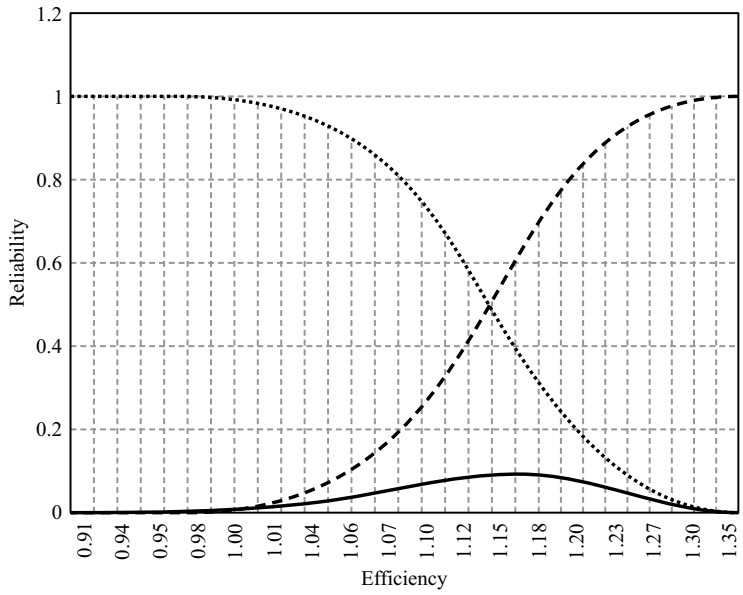

- Density function

- - Distribution function

....... Survival function

Fig. 7. Scheme of the optimal investment resource allocation where the values of most likely possibilities coincide with the highest values of intervals: efficiency possibilities (a), utility function (b), surface contact point (c), optimal solution (d), and the distribution of the probability of possibilities (e) 


\section{Conclusions}

The capacity of value-creation is becoming an exceptional indicator of the efficiency of companies as well as individual activities. Since development resources of companies are limited, their regeneration and rational distribution directly determine the performance of a company.

Uncertainty and its consequences require improvement of uncertainty evaluation algorithms by quantitative measurement of uncertainty and its risk consequences. The stochastic network concept proposed in this paper should become a constructive means for value creation through the rational allocation of development resources of a company. The stochastic optimisation scheme is a multi-criteria optimisation system, because here, the stochastic utility function includes efficiency, reliability and risk indicators that are practically formed by taking into account the relevant indicators of operational resources, factors and interoperability.

The adequate investment portfolio model discussed in this paper works as a means of general interactive harmonization of interest aspirations and disclosure of their incompatibility. In practice, the capacity of the adequate portfolio scheme has been tested at the level of an individual company and its integration strategy. The optimal distribution of the marginal development resource unit between integration strategy attributes was obtained.

The adequate portfolio technique and the stochastic network concept used by the authors of this paper in conjunction with the stochastically informed expertise gives a possibility to solve complex stochastic optimisation problems and valuate the reliability of designed solutions as an economic factor.

In this paper, an original solution to the problem concerning the allocation of development resources of a company among integration strategy attributes is proposed, when the reliability of the development opportunities becomes the resource and factor of those opportunities.

There are several limitations to this study. The interplay of integration strategy attributes - product quality, the reliability of delivery, process flexibility and cost leadership is a sufficiently complex situation; besides, the studies excluded quantitative valuation and statistical analysis. In the future research, it is essential to develop the simulation system of the interplay that would allow us to reveal its existence and quantitative valuation possibilities.

\section{References}

Adner, R.; Kapoor, R. 2010. Value creation in innovation ecosystems: how the structure of technological interdependence affects firm performance in new technology generations, Strategic Management Journal 31(3): 306-333. http://dx.doi.org/10.1002/smj.821

Bechmann, A.; Stine, L. 2013. Mapping actor roles in social media: different perspectives on value creation in theories of user participation, New Media \& Society 15(5): 765-781.

http://dx.doi.org/10.1177/1461444812462853 
Bilge, P.; Badurdeen, F.; Seliger, G.; Jawashir, I. S. 2014. Model-based approach for assessing value creation to enhance sustainability in manufacturing, Procedia CIRP 17: 106-111. http://dx.doi.org/10.1016/j.procir.2014.02.031

Flynn, B.; Schroeder, R. G.; Flynn, J. 1999. World class manufacturing: an investigation of Hayes and Wheelwright's foundation, Journal of Operations Management 17(3): 249-269.

http://dx.doi.org/10.1016/S0272-6963(98)00050-3

Hayes, R. H.; Upton, D. M. 1998. Operations-based strategy, California Management Review 40(4): 8-20. http://dx.doi.org/10.2307/41165962

Hiraishi, K. 2015. Simulating Markovian stochastic Petri Nets by difference equations with interval parameters, Discrete Event Dynamic Systems 25: 365-386.

http://dx.doi.org/10.1007/s10626-014-0188-4

Hou, G.; Chang, J.; Shou, K.; Li, M. 2014. Embedded system modeling and verification based on deterministic and stochastic Petri Net, Journal of Computational Information Systems 10(12): 5051-5058.

Kim, J. S.; Arnold, P. 1992. Manufacturing competence and business performance: a framework and empirical analysis, International Journal of Operations \& Production Management 13(10): 4-25. http://dx.doi.org/10.1108/01443579310045518

Klibi, W.; Alain, M.; Adel, G. 2010. The design of robust value-creating supply chain networks: a critical review, European Journal of Operational Research 203(2): 283-293.

http://dx.doi.org/10.1016/j.ejor.2009.06.011

Lefebvre, D. 2011. About the stochastic and continuous Petri Nets equivalence in the long run, Nonlinear Analysis: Hybrid Systems 5: 394-406. http://dx.doi.org/10.1016/j.nahs.2011.02.001

London, T.; Ravi, A.; Sheth, S. 2010. Creating mutual value: lessons learned from ventures serving base of the pyramid producers, Journal of Business Research 63(6): 582-594.

http://dx.doi.org/10.1016/j.jbusres.2009.04.025

Maine, E.; Lubik, S.; Garnsey, E. 2012. Process-based vs. product-based innovation: value creation by nanotech ventures, Technovation 32(3-4): 179-192.

http://dx.doi.org/10.1016/j.technovation.2011.10.003

Marin, A.; Balsamo, S.; Harrison, P. G. 2012. Analysis of stochastic Petri Nets with signals, Performance Evaluation 69(11): 551-572. http://dx.doi.org/10.1016/j.peva.2012.06.003

Miller, J. G.; Roth, A. V. 1994. A taxonomy of manufacturing strategies, Management Science 40(3): 285-304. http://dx.doi.org/10.1287/mnsc.40.3.285

Porter, M. E. 1996. What is strategy?, Harvard Business Review 74(6): 61-78.

Rosenzweig, E. D.; Roth, A. V.; Dean, J. W. 2003. The influence of an integration strategy on competitive capabilities and business performance: an exploratory study of consumer products manufacturers, Journal of Operations Management 21(4): 437-456.

http://dx.doi.org/10.1016/S0272-6963(03)00037-8

Roth, A. V.; Miller, J. G. 1992. Success factors in manufacturing, Business Horizons 35(4): 73-81. http://dx.doi.org/10.1016/S0007-6813(05)80165-X

Rutkauskas, A. V. 2006. Adequate investment portfolio anatomy and decisions, applying imitative technologies, Economics 75: 52-76.

Rutkauskas, A. V.; Račinskaja, I. 2013. Integrated intelligence and knowledge, innovation and technology management, nurturing country universal sustainable development, in 2nd International Scientific Conference "Problems of Modern Economy: Global, National and Regional Context”, 23-24 May 2013, Grodno, Belarus.

Rutkauskas, A. V.; Račinskaja, I.; Stasytytè, V. 2014. Optimization of integral knowledge, innovation and technologies cluster structure, Asian Journal of Business and Management 2(1): 42-52. 
Rutkauskas, A. V.; Stasytytè, V. 2011. Optimal portfolio search using efficient surface and threedimensional utility function, Technological and Economic Development of Economy 17(2): 291312. http://dx.doi.org/10.3846/20294913.2011.580589

Schrödl, H.; Turowski, K. 2014. Risk management in hybrid value creation, Decision Support Systems 58: 21-30. http://dx.doi.org/10.1016/j.dss.2012.12.042

Vickery, S. K.; Droge, C.; Markland, R. E. 1994. Strategic production competence: convergent, discriminant and predictive validity, Production and Operations Management 3(4): 308-318. http://dx.doi.org/10.1111/j.1937-5956.1994.tb00127.x

Wang, Z.; Maen, A.; Adjallah, H. K. 2014. Coloured stochastic Petri Nets modelling for the reliability and maintenance analysis of multi-state multi-unit systems, Journal of Manufacturing Technology Management 25(4): 476-490. http://dx.doi.org/10.1108/JMTM-04-2013-0045

Ward, P. T.; Durray, R.; Leong, G. K.; Sum, C. C. 1995. Business environment, operations strategy and performance: an empirical study of Singapore manufacturers, Journal of Operations Management 13(2): 99-115. http://dx.doi.org/10.1016/0272-6963(95)00021-J

Weaven, S.; Grace, D.; Dant, R.; Brown, J. R. 2014. Value creation through knowledge management in franchising: a multi-level conceptual framework, Journal of Services Marketing 28(2): 97-104. http://dx.doi.org/10.1108/JSM-09-2013-0251

White, G. P. 1996. A meta-analysis of manufacturing capabilities, Journal of Operations Management 14(4): 315-331. http://dx.doi.org/10.1016/S0272-6963(96)00096-4

Aleksandras Vytautas RUTKAUSKAS. Professor at the Department of Finance Engineering, Vilnius Gediminas Technical University. His research interests are: investment portfolio management in capital and exchange markets, risk and uncertainty, sustainable development, integrated value and risk management.

Aleksandr OSTAPENKO. PhD candidate at the Department of Economics and Management of Enterprises, Vilnius Gediminas Technical University. His research interests are: strategy development of companies and expert estimations. 